\title{
Modos de vida, sostenibilidad y patrimonialización del territorio purépecha, México
}

\author{
Eugenia Maria Azevedo Salomão1 \\ Luis Alberto Torres Garibay²
}

Resumen: El trabajo reflexiona sobre temas emergentes vinculados a modos de vida, sostenibilidad y patrimonialización con el ejemplo de un grupo étnico mexicano - el purépecha - con el propósito de contribuir a una gestión sostenible. El andamiaje teórico-metodológico se apoya en los paradigmas del pensamiento complejo y de la transdisciplina como el camino viable para una mirada más amplia sobre el tema. Además de la revisión bibliográfica y documental, el trabajo se fundamenta en el conocimiento de la cultura purépecha a partir de proyectos de investigación realizados con apoyo de instituciones mexicanas por más de dos décadas. La investigación en campo ha sido factor imprescindible para identificar rasgos culturales y problemáticas en la gestión patrimonial. Los principales aportes del trabajo radican en la identificación y entendimiento de la interdependencia entre las dimensiones socio-culturales, ambientales y patrimoniales de la cultura purépecha.

Palabras-clave: Pensamiento complejo; transdisciplina; patrimonio material e inmaterial; cultura Purépecha.

\section{Modos de vida, sustentabilidade e patrimonialização do território purépecha, México}

Resumo: $O$ trabalho reflete sobre temas emergentes vinculados a modos de vida, sustentabilidade e patrimonialização, com o estudo de caso de um grupo étnico mexicano - o Purépecha- com o propósito de contribuir a uma gestão sustentável. A construção teórico-metodológica se apoia nos paradigmas do pensamento complexo e transdisciplinar como o caminho viável para um olhar mais amplo sobre o tema. Além da revisão bibliográfica e documental, o trabalho fundamenta-se no conhecimento da cultura purépecha a partir de projetos de pesquisa realizados com apoio de instituições mexicanas por mais de duas décadas. A pesquisa em campo tem sido fator imprescindível para identificar traços culturais e problemáticas na gestão patrimonial. Os principais resultados do trabalho residem na identificação e entendimento da interdependência entre as dimensões socioculturais, ambientais e patrimoniais da cultura purépecha.

Palavras-chave: Pensamento complexo; transdisciplina; patrimônio material e imaterial; cultura Purépecha.

\section{Way of life, sustainability and heritage the Purépecha territory, México}

\begin{abstract}
This work reflects on emerging issues related to lifestyle, sustainability and heritage, taking as example a Mexican ethnic group, the Purépecha. The purpose is to contribute to sustainable management. The theoreticalmethodological scaffolding is based on the paradigms of complex thought and transdisciplinarity as the viable path for a broader view on the subject. In addition to the bibliographic and documentary review, the work is based on the knowledge of the Purépecha culture from research projects carried out with the support of Mexican institutions for more than two decades. Field research has been an essential factor in identifying cultural and problematic features in asset management. The main output of the work lies in the identification and understanding of the interdependence between the socio-cultural, environmental and heritage dimensions of the Purépecha culture.
\end{abstract}

Keywords: Complex thougt; transdisciplinarity; material and immaterial heritage; Purépcha culture.

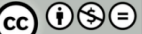

DOI: https://doi.org/10.26512/patryter.v3i5.25783

Como citar este artigo: Azevedo-Salomão, E. M.; Torres-Garibay, L. A. (2020). Modos de vida, sostenibilidad y patrimonialización del territorio purépecha, México. PatryTer - Revista Latinoamericana e Caribenha de Geografia e Humanidades, 3 (5), 1-13. DOI: https://doi.org/10.26512/patryter.v3i5.25783

Recebido: 4 de julho de 2019. Aceite: 28 de setembro de 2019. Publicado: 01 de março de 2020.

${ }^{1}$ Doctora en Arquitectura por la Universidad Nacional Autónoma de México. ORCID: http://orcid..org/00019236-0481 E-mail: eazevedosa@yahoo.com.mx.

2 Doctor en Arquitectura por la Universidad Nacional Autónoma de México. ORCID: http://orcid..org/0000-00023685-9023 E-mail: latg47@,yahoo.com.mx. 


\section{Introducción}

El territorio cultural purépecha está ubicado en el Estado de Michoacán, México, y comprende la cuenca del lago de Pátzcuaro así como la Sierra, y pequeños grupos de laderas conocidas como la Cañada y la Ciénega de Zacapu. Los habitantes de estas regiones son predominantemente purépechas, ya que conservan tradiciones socioculturales y mantienen costumbres de organización de trabajo y vida social muy propias. Son áreas con fuertes antecedentes mesoamericanos, que fueron reorganizadas a la llegada de los españoles pero que mantuvieron modos de vida arraigados a tradiciones locales.

Este trabajo propone la reflexión en torno a temas emergentes vinculados a modos de vida, sostenibilidad y patrimonialización con el ejemplo de este grupo étnico latinoamericano - el purépecha- con el propósito de contribuir a la resignificación de posturas teóricas y prácticas en la conservación y gestión del patrimonio cultural material e inmaterial. Se parte de la premisa que la sostenibilidad es una condición necesaria para el conjunto de las actividades humanas; ésta debe incluir una visión holística que englobe la naturaleza, lo social y cultural (García y Vaca, 2018). Así, es fundamental tener en cuenta que los espacios de relación social y soporte de la memoria deben contar con una conservación sostenible que garanticen una mejor calidad de vida y la protección del hábitat en lo natural, material y simbólico.

Para lograr la cabal comprensión de la relación indisociable entre cultura, modos de vida, sostenibilidad y patrimonialización, el andamiaje teórico-metodológico se apoya en los paradigmas del pensamiento complejo y de la transdisciplina como el camino viable para una mirada más amplia sobre el tema. Se considera que el pensamiento complejo y la transdisciplina ofrecen instrumentos para incorporar el conocimiento tradicional y la memoria histórica en el estudio de la cultura purépecha, sus modos de vida, el patrimonio cultural y el entorno que lo contiene. Varios autores están de acuerdo que el pensamiento complejo permite la actualización o reconceptualización de los valores culturales desde una perspectiva más amplia, posibilitando muchas alternativas para investigar y llevar a la práctica proyectos para la conservación y gestión sostenibles de los patrimonios culturales (López, Platas, Romero y Salceda, 2014; Azevedo y Fuentes, 2017).

El texto inicia reflexionando sobre los paradigmas del pensamiento complejo, para después incursionar en las características peculiares de la cultura purépecha referentes a su cosmogonía, modos de vida y patrimonio cultural. En otro apartado se cuestiona sobre los riesgos de la patrimonialización y se concluye recalcando la necesidad de una gestión sostenible de este territorio cultural, en la cual impere una actitud de transversalidad en la lectura de la problemática que presenta.

\section{Paradigmas del pensamiento complejo y patrimonio cultural}

En el abordaje del patrimonio cultural, interactúan un creciente número de factores que condicionan su conocimiento e intervención y revelan un alto grado de complejidad. Por lo tanto, se considera pertinente recurrir al enfoque integrador del pensamiento constructivista, cuya postura aspira cimentar el conocimiento a partir de un proceso de organización-desorganización y de reorganizaciones sucesivas. A partir de este enfoque constructivista surge la noción del pensamiento complejo, entre cuyos principales teóricos pueden mencionarse a Jean Piaget y Edgar Morin (López, Platas, Romero y Salceda, 2014).

De la corriente de pensamiento constructivista se desprende la "teoría de los sistemas complejos” de Rolando García y Rafael López Rangel en el ámbito de la arquitectura y urbanismo (López, Platas, Romero y Salceda, 2014). El pensamiento complejo y la teoría de los sistemas complejos, no conciben de manera lineal el proceso del conocimiento (Morin, 2007; López et al., 2014; Ribeiro, 2014). Es fundamental ahondar en el funcionamiento del complejo cognoscitivo.

Rafael López Rangel (López, Platas, Romero y Salceda, 2014) dice que para:

Construir estrategias de conocimiento que no
conciban la realidad a través de esquemas
aprioristas o de ordenamientos, sumas, modelos,
normas estáticas, sino mediante estrategias que
sean capaces a través de dialógicas, recursividades y
el desentrañamiento del comportamiento del todo y
de las partes -en operaciones sucesivas-. (p. 21)

El pensador francés Edgar Morin (2007) sostiene que el pensamiento complejo es un método de pensamiento nuevo, válido para comprender la naturaleza, la sociedad, reorganizar la vida humana, y para buscar soluciones a las crisis de la humanidad contemporánea. Morin (2007) ve el mundo como un todo indisociable, donde el espíritu individual de las personas posee conocimientos ambiguos, desordenados, que necesita acciones retroalimentadoras y plantea re 
pensar el mundo de forma transdisciplinaria en el marco de un diálogo entre saberes, centrado en el problema antropológico. Al respecto dice: "[...] el pensamiento simple resuelve los problemas simples sin problemas de pensamiento. El pensamiento complejo no resuelve, en sí mismo, los problemas, pero constituye una ayuda para la estrategia que pueda resolverlos" (Morin, 2007, p. 118).

Para Morin (2007) la innovación presupone una cierta desorganización y relajamiento de tensiones, estrechamente vinculadas con la acción de un principio reorganizado; además, se opone al aislamiento de los objetos del conocimiento, los restituye a su contexto, los reinserta en la globalidad a la que pertenecen. Propone una integración transdisciplinar mediante tres principios: el "dialógico" propone que la coherencia de un sistema surge de la paradoja y del encuentro de lógicas que se contraponen y se complementan; la "recursividad organizacional" es un proceso en el cual los productos y los efectos son, al mismo tiempo, causas y productores de aquello que los produce y el "principio hologramático" se refiere a que en un holograma físico, el menor punto de la imagen del holograma contiene la casi totalidad de la información del objeto representado, "[...] no solamente la parte está en el todo, sino que el todo está en la parte" (Morin, 2007, p. 107).

Como se puede observar, el pensamiento complejo y la transdisciplina posibilitan incorporar en los estudios sobre patrimonio cultural (material e inmaterial), tanto los conocimientos tradicionales y la memoria histórica como el paisaje en el cual están insertos. Se coincide con varios autores, en afirmar que el pensamiento complejo permite la actualización o reconceptualización de los valores culturales desde una perspectiva amplia. Desde la visión de la complejidad, se puede llevar a la práctica de manera eficaz, proyectos para la conservación y desarrollo sostenibles de los patrimonios culturales (Azevedo y Vale, 2018; Azevedo y Fuentes, 2017).

El pensamiento complejo y la transdisciplina ofrecen instrumentos para incorporar el conocimiento tradicional y la memoria histórica en el estudio del patrimonio cultural y el paisaje que lo contiene. Como lo han sugerido varios autores, el pensamiento complejo permite la actualización o reconceptualización de los valores culturales desde una perspectiva mucho Similiy llevar a la práctica proyectos para la conservación y desarrollo sostenible de los patrimonios culturales (Azevedo y Fuentes, 2017)

Una vez expuestos los principios básicos del pensamiento complejo, se invita a pensar que cualquier intervención en el hábitat, independientemente de su escala, es parte de un sistema mayor comprendido por el contexto social, económico, cultural y físico-geográfico. No perder de vista que cada intervención es fruto de un proceso único, particular, condicionado por variables específicas; son procesos dinámicos y diversos que cambian constantemente en función del contexto cultural propio. Esta visión nos permite valorar adecuadamente el recurso patrimonial y plantear caminos y alternativas desde sus propias dinámicas y fuerzas (López, Platas, Romero y Salceda, 2014).

Por lo anterior, se considera la necesidad de abordar los problemas vinculados al patrimonio cultural (material e inmaterial) y natural, modos de vida y sostenibilidad, bajo esta perspectiva. Es decir, debemos guiar nuestras actividades de conservación e intervención de los espacios habitables patrimoniales contemplando toda su complejidad, extrapolando criterios tradicionalistas enfocados fundamentalmente en aspectos físicos, fuera de sus realidades complejas.

\section{Cultura purépecha: una mirada al pasado y presente}

La actual cultura purépecha tiene sus antecedentes vinculados a la antigua sociedad tarasca o purépechai que se desarrolló durante el periodo posclásico tardío (1200-1500 dC) en el Occidente de México. En la cuenca del lago de Pátzcuaro se asentó esta cultura que se extendió a otras áreas del actual estado de Michoacán como en la Sierra Purépecha, la cuenca del Balsas, en la región de Uruapan y especialmente en las cuencas de Zacapu y Cuitzeo (Figuras 1, 2 y 3).

Figura 1 - Ubicación de la cultura purépecha en el Estado de Michoacán, México

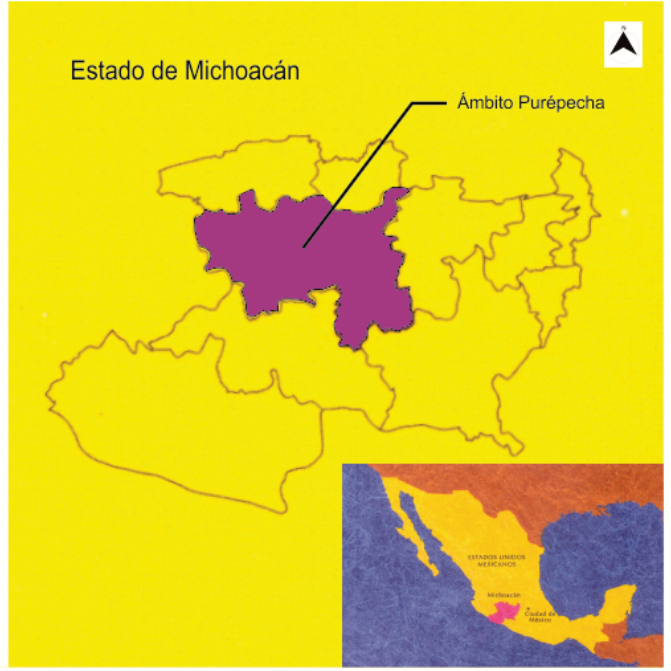

Fuente: Elaboración de los autores con base en Guía de arquitectura y paisaje Michoacán (Guzmán, 2007).

PatryTer | ISSN: 2595-0169 | vol. 3 | n. 5 | março 2020 | pp. 1-13| Artigo 
Figura 2 - Sitio arqueológico de Tzintzuntzan en la cuenca lacustre de Pátzcuaro

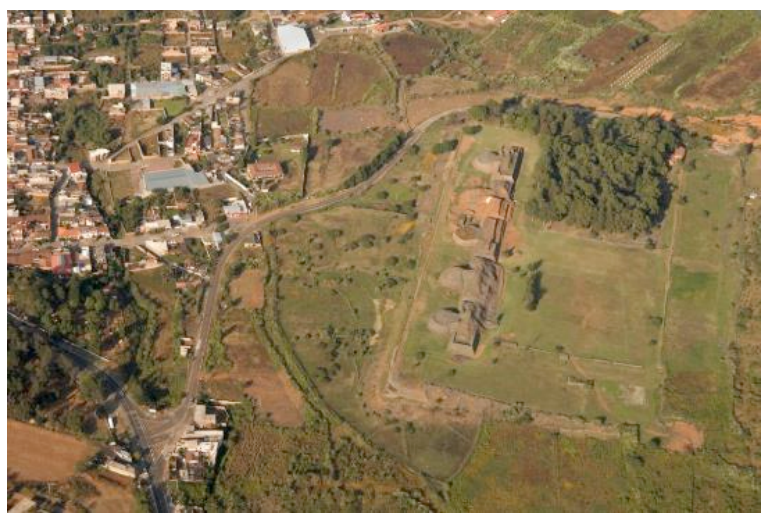

Fuente: Archivo Torres Salomao (2009).

Figura 3 - Sitio arqueológico de Tzintzuntzan en la cuenca lacustre de Pátzcuaro

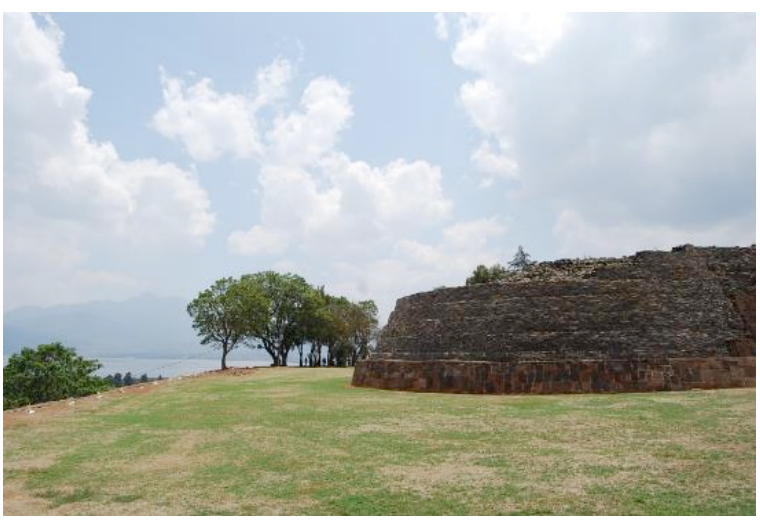

Fuente: Archivo Torres Salomao (2017).

La población indígena prehispánica constaba de grupos de varias etnias, sin embargo, los tarascos controlaban el territorio descrito desde sus centros administrativos en la cuenca lacustre de Pátzcuaro. Inclusive se han detectado en los estados de Guanajuato y Jalisco vestigios de cerámica policromada, lo que puede ser el indicio de relaciones comerciales, culturales, ideológicas y tal vez de dominio (Fernández-Villanueva y Cárdenas, 1999). El documento que relata la historia prehispánica de Michoacán es la Relación de Michoacán, una fuente valiosa para entender los modos de vida de la cultura en la etapa prehispánica, a pesar de representar el punto de vista del grupo en el poder y de que está presente la mirada del fraile Jerónimo de Alcalá quien compila e interpreta la información dada por los tarascos (Paredes, 2017).

La conquista española en el siglo XVI trajo cambios fuertes en los modos de vida y reorganización de los asentamientos humanos tarascos. La conquista formal sobre el Estado Tarasco fue en 1521 estando a cargo Cristóbal de Olid. Uno de los programas que más repercusiones tuvieron en las transformaciones del territorio tarasco fueron las Congregaciones llevadas a cabo de manera muy temprana (1523-1524) como parte del proceso evangelizador y de control del territorio. Esta política española de congregar los indígenas en asentamientos urbanos regulados, era contraria a los modos de vida de los naturales, acostumbrados a la vida al aire libre y a convivir bajo un mismo techo las familias extensas (Paredes, 2008).

A partir del encuentro cultural de los españoles con los indígenas mesoamericanos, se estructuraron nuevas instituciones y prácticas sociales que fueron impuestas desde las primeras décadas de la conquista. En lo referente a la conquista espiritual, ésta impuso el catolicismo a través de una campaña evangelizadora sin precedentes, adoctrinando a los pueblos indígenas (como el purépecha) en toda Mesoamérica. No obstante la imposición de un nuevo orden, muchas de las costumbres milenarias permanecieron hasta nuestros días (Figuras 4 y 5).

Figura 4 - Paisaje del territorio cultural purépecha. Cuenca lacustre de Pátzcuaro

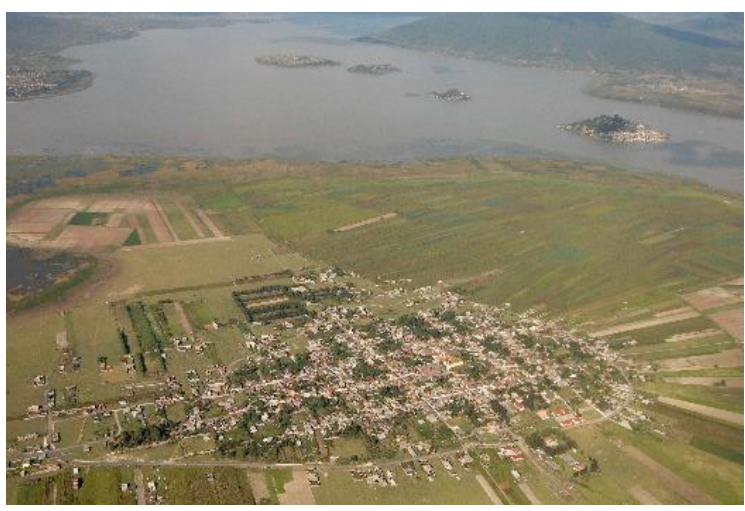

Fuente: Archivo Torres Salomao (2009).

Figura 5 - Paisaje del territorio cultural purépecha. Sierra purépecha

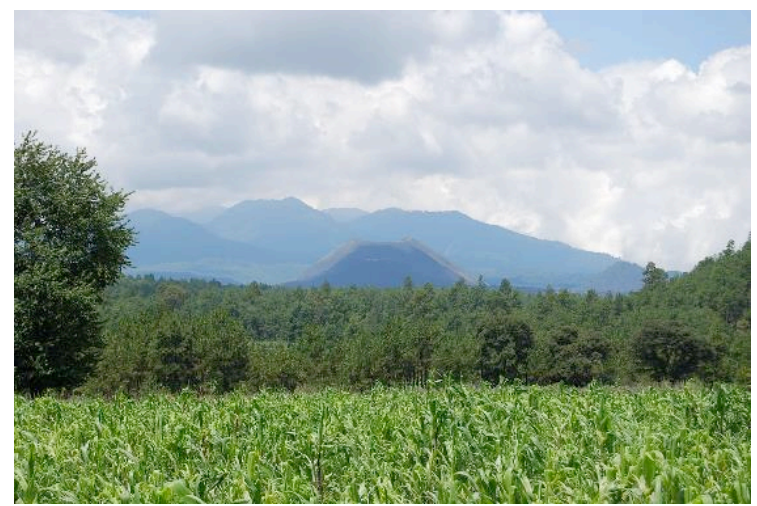

Fuente: Archivo Torres Salomao (2004). 


\section{Cosmovisión y naturaleza}

En la cultura purépecha como en otras culturas indígenas americanas, el vínculo con la naturaleza es básico. La visión cósmica celeste se trasplanta a la terrenal y de ella al inframundo, vinculadas a rituales dedicados a los dioses que rigen las fuerzas y los fenómenos de la naturaleza. Sostiene Blanca Cárdenas (2006) que: “[...] la construcción cósmica celeste, representada en los mitos de la creación de los dioses del cielo, se reproduce en los mitos de la creación terrestre: de la naturaleza y del hombre, así como en construcciones arquitectónicas consagradas a las divinidades" (p. 23).

Los rituales del pueblo purépecha tienen un fuerte vínculo con los cambios de las estaciones, con la fertilidad de la tierra, con el carácter cíclico del tiempo. Este conocimiento de la naturaleza es lo que hace con que algunos rituales se realicen en lugares de la naturaleza como en los ojos de agua, en el cerro, en los plantíos de maíz, asociados a los periodos de lluvias y secas (Castilleja, 2007). La cosmovisión se expresa a través de un modo de

\section{Modos de vida y habitabilidad}

Los asentamientos purépechas siguen siendo hasta la actualidad pueblos relacionados con las actividades agrícolas. La vida se desarrolla alrededor del ciclo agrícola impuestos por la siembra y la cosecha. La mayoría de las comunidades viven del cultivo de tierras comunales, pequeña propiedad o tierras ejidales; producen maíz, trigo, fríjol, calabaza y hortalizas, que son para el consumo familiar y en algunas ocasiones se vende en la propia comunidad o en pueblos cercanos. En la unidad doméstica se dan otras actividades que complementan el trabajo agrícola; por ejemplo, la producción artesanal en algunas comunidades ha sido más redituable que la agricultura por lo que se dedican más a esta actividad. También en la cuenca lacustre de Pátzcuaro, la pesca es una actividad importante de algunos pueblos. Algunos pobladores se dedican a la albañilería y al comercio local (Castilleja, 2008; Azevedo, 2008). La familia es la base de la organización social y la división del trabajo es de acuerdo al sexo y edad (Figuras 8 y 9).

Figuras 6 y 7 - Fiesta del Corpus Christi en Sevina, Sierra purépecha
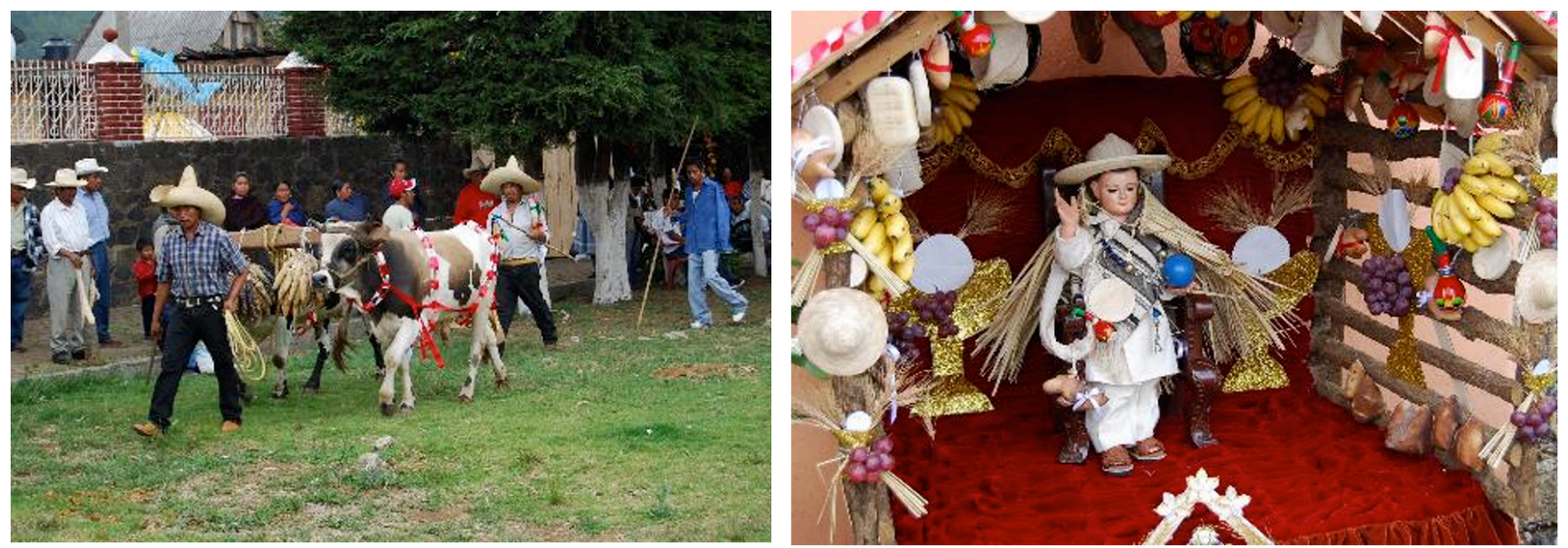

Fuente: Archivo Torres Salomao (2010).

pensar simbólico con completa adaptabilidad al entorno. Este pensamiento mítico proporciona la apropiación del mundo natural, social e individual como respuesta adaptativa al medio donde conectan con los mecanismos de sobrevivencia y de conservación de los recursos naturales. Actualmente hay tres elementos centrales de esta festividad purépecha: los oficios como elementos de distinción en la participación e integración de la comunidad, la importancia de la integración del cerro en el espacio y tiempo ritual y los bienes que constituyen las ofrendas en estrecha asociación con el sentido propiciatorio de la celebración y para lograr una buena temporada de lluvias (Figuras 6 y 7).
La unidad doméstica purépecha conservó a lo largo de la historia, características constructivas, espaciales y de uso de las etapas prehispánica y virreinal; hay una íntima relación con la naturaleza y el espacio abierto asume importancia fundamental. El espacio cubierto es reducido siendo utilizado nada más para actividades propiamente íntimas. La concepción espacial se caracteriza por espacios construidos alrededor de patios y las áreas de cultivo forman parte de la unidad doméstica. Al respecto de los espacios abiertos, en la lengua tarasca o purépecha, el término que expresa el espacio abierto es el ekuarho que se traduce como patio. También el término ekuarho es empleado en algunas áreas purépechas, refiriéndose al solar, al espacio productivo, 
entendiendo éste como la parte de la casa en que se cultiva y crían animales. El inchacutini ekuarbo, que significa entrar al lugar más adentro, se refiere precisamente a este espacio abierto productivo, asociado a la vida privada, es una prolongación de la habitación purépecha (Azevedo, 2008). siendo utilizado nada más para actividades propiamente íntimas. La concepción espacial se caracteriza por espacios construidos alrededor de patios y las áreas de cultivo forman parte de la unidad doméstica. Al respecto de los espacios abiertos, en la lengua tarasca o purépecha, el

Figuras 8 y 9 - Fiesta del Corpus Christi en Sevina, Sierra purépecha
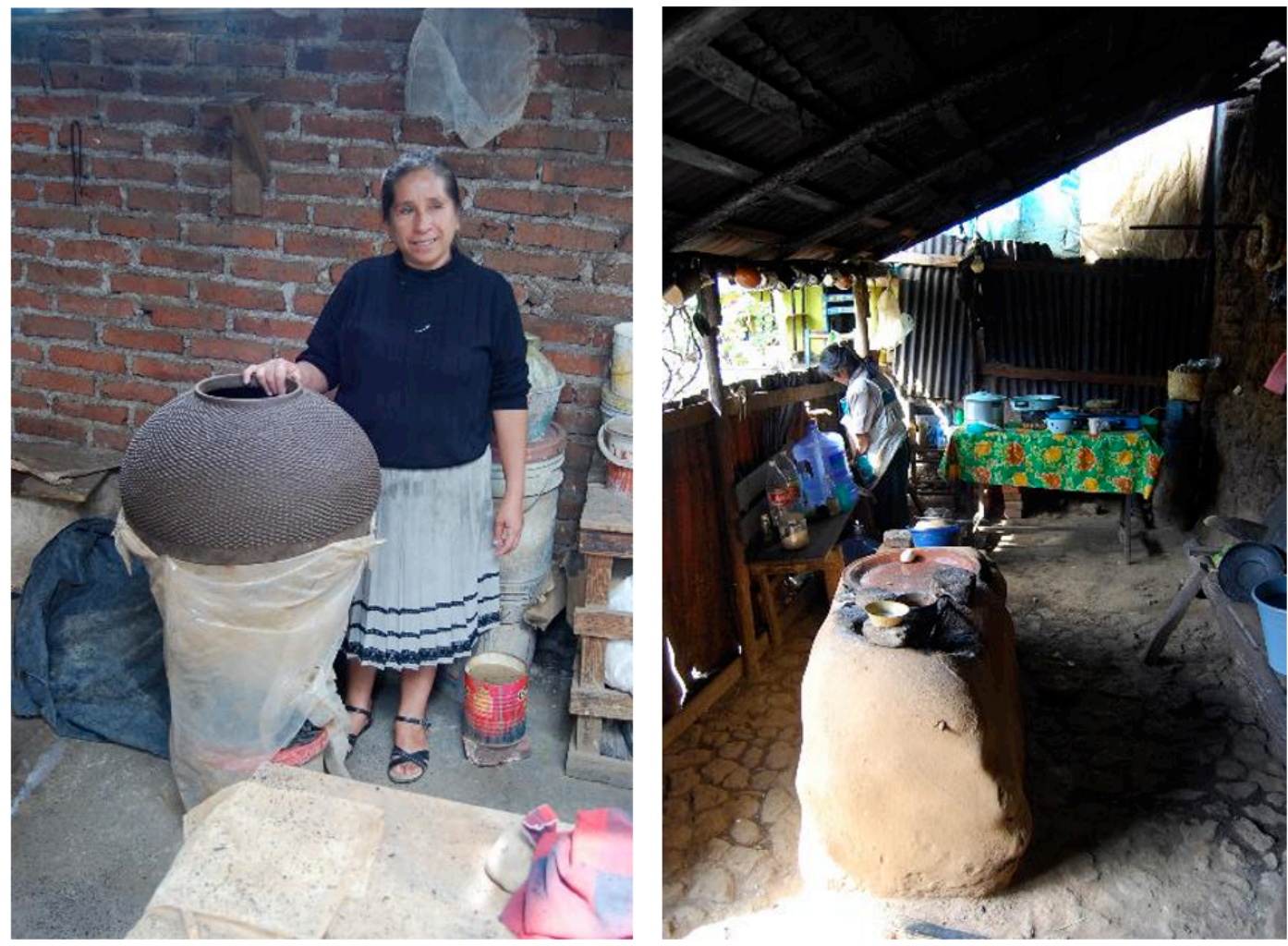

Fuente: Archivo Torres Salomao (2010).

Por lo tanto, la unidad doméstica va mucho más allá de espacios a cubierto, pues la vida cotidiana y la gran mayoría de las actividades se desarrollan al aire libre. La espacialidad de la vivienda está conformada de espacios exteriores delimitados por cercas de piedra o por muros de adobe u otro material. En su interior está el patio en el cual están áreas de estar y de servicios (baños, letrinas, hornos, áreas de lavado de ropa), el solar en donde se siembran la milpa, hortalizas y se cultivan árboles frutales. Los espacios a cubierto como los cuartos y las cocinas, son oscuros y reducidos. Se destacan los espacios de transición como los portales y tejados que sirven en la mayoría de las veces de cocinas, talleres o áreas para el lavado de la ropa y trastes.

La unidad doméstica purépecha conservó a lo largo de la historia, características constructivas, espaciales y de uso de las etapas prehispánica y virreinal; hay una íntima relación con la naturaleza y el espacio abierto asume importancia fundamental. El espacio cubierto es reducido término que expresa el espacio abierto es el ekuarho que se traduce como patio. También el término ekuarho es empleado en algunas áreas purépechas, refiriéndose al solar, al espacio productivo, entendiendo éste como la parte de la casa en que se cultiva y crían animales. El inchacutini ekuarho, que significa entrar al lugar más adentro, se refiere precisamente a este espacio abierto productivo, asociado a la vida privada, es una prolongación de la habitación purépecha (Azevedo, 2008).

Por lo tanto, la unidad doméstica va mucho más allá de espacios a cubierto, pues la vida cotidiana y la gran mayoría de las actividades se desarrollan al aire libre. La espacialidad de la vivienda está conformada de espacios exteriores delimitados por cercas de piedra o por muros de adobe u otro material. En su interior está el patio en el cual están áreas de estar y de servicios (baños, letrinas, hornos, áreas de lavado de ropa), el solar en donde se siembran la milpa, hortalizas y se cultivan árboles frutales. Los espacios a cubierto como los cuartos y las cocinas, son oscuros y 
reducidos. Se destacan los espacios de transición como los portales y tejados que sirven en la mayoría de las veces de cocinas, talleres o áreas para el lavado de la ropa y trastes.

Como se puede atestiguar, el hábitat purépecha evidencia un profundo conocimiento del ecosistema, el cual ha sido transmitido de generación en generación; en su manufactura predominan los materiales orgánicos como la tierra y la madera; tiene su antecedente en la vivienda purépecha prehispánica a la cual los europeos también aportaron elementos como parte del proceso de mestizaje cultural. Es una arquitectura que se adecua al medio físico geográfico donde se ubica, incluye además una serie de actividades que en muchos casos han perdurado a través de los años, aunque con obvias modificaciones originadas por el avance tecnológico o los patrones culturales que llegan del exterior. También expresa una forma de vida familiar y de sociabilidad hacia la comunidad, perpetuando una forma de vida al aire libre, característica del mundo mesoamericano y persistente hasta nuestros días (Figuras 10 y 11).

Las características de la unidad doméstica se reflejan en la morfología de los asentamientos que en general tienen baja densidad constructiva con vegetación en los corazones de manzanas. Actualmente se observa un proceso de subdivisión de la lotificación, por el cambio de la familia extensa a la nuclear. La mayor concentración constructiva se observa en los núcleos de los asentamientos y sigue prevaleciendo una baja densidad en la periferia. Es importante comentar que hoy día, los cambios en los modos y formas de vida, el acelerado proceso de migración a nivel nacional y a los Estados Unidos de América, han propiciado cambios sustanciales en algunas comunidades purépechas, que se ha reflejado en la arquitectura y configuración espacial de los asentamientos humanos (Figuras 12 y 13).

Figura 10 - Ejemplo de la espacialidad y constructividad de la vivienda purépecha. Vivienda de madera conocida como "troje" en la Sierra purépecha

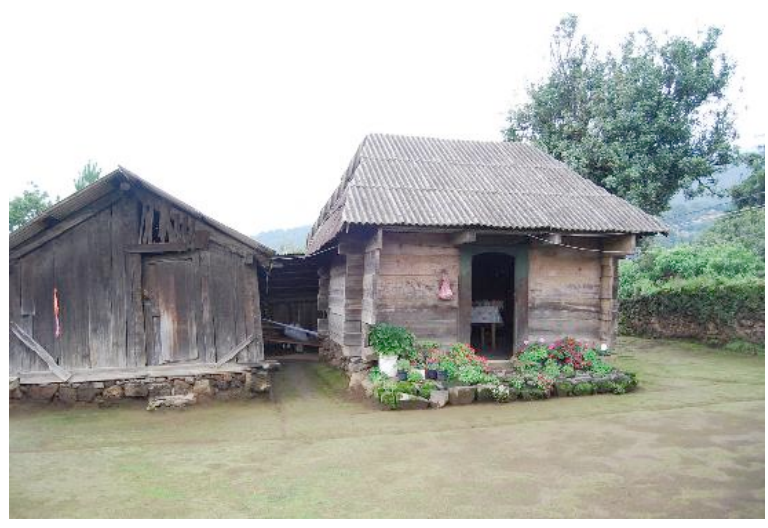

Fuente: Archivo Torres Salomao (2010).
Figura 11 - Ejemplo de la espacialidad y constructividad de la vivienda purépecha. Vivienda de adobe de la cuenca lacustre de Pátzcuaro.

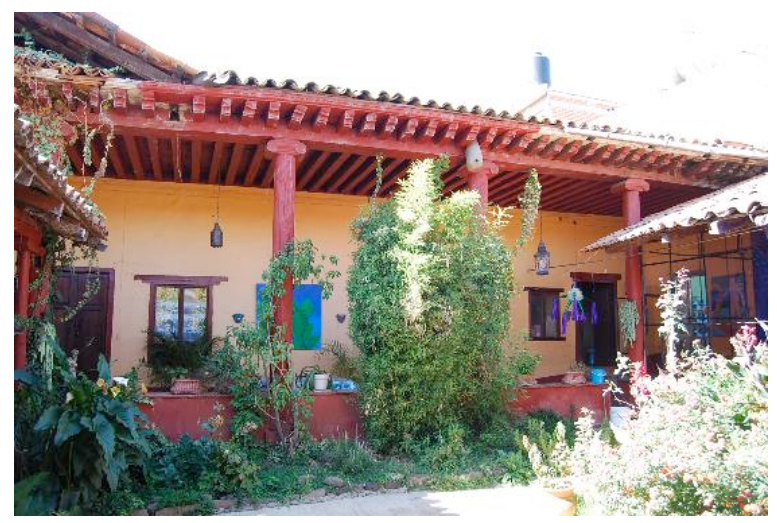

Fuente: Archivo Torres Salomao (2007).

Figuras 12 y 13 - Asentamientos purépechas. En la primera imagen abajo observa la morfología del asentamiento de Aranza en la Sierra purépecha, en la segunda imagen abajo el asentamiento de Jarácuaro en la cuenca lacustre de Pátzcuaro en donde se observan las transformaciones de las viviendas

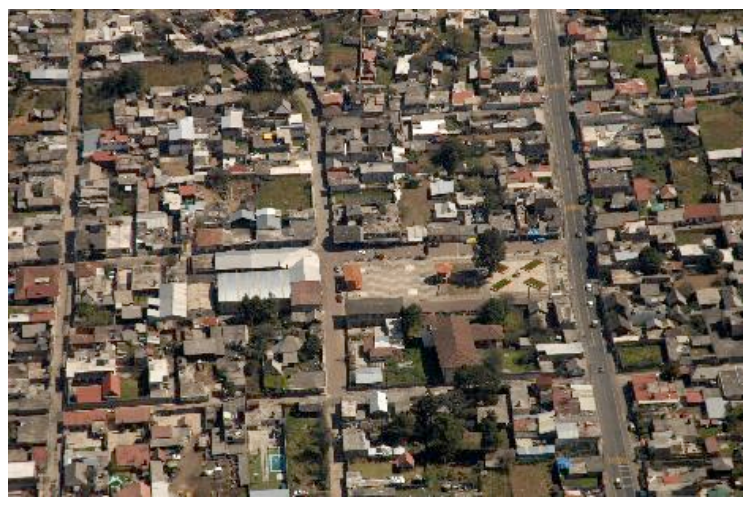

Fuente: Archivo Torres Salomao (2009).

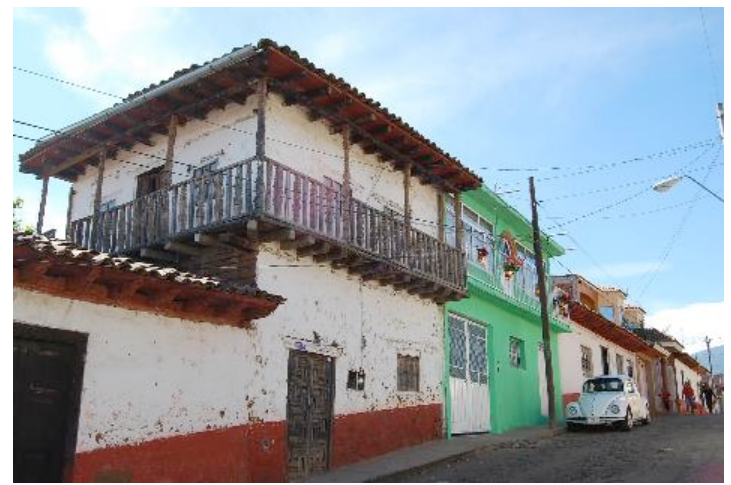

Fuente: Archivo Torres Salomao (2007). 


\section{E1 sentido comunitario y la costumbre}

El pueblo purépecha es esencialmente social y de acuerdo a su cosmovisión vive en la conciencia de que su comunidad se extiende más allá de las fronteras de la vida y la muerte.

Esta actitud socio comunitaria se manifiesta en sus actividades cotidianas y alcanza su máxima expresión en las fiestas. La "fiesta" es un aspecto que merece especial atención, pues es la forma como la comunidad se interrelaciona y el sentido grupal de esta cultura queda manifiesto, así como también la manera en que el purépecha comparte su alegría y expresa su "liberalidad" (Jacinto, 1988).

Con relación a la concepción del uso del espacio en sus tres dimensiones (arquitectura, asentamiento humano y territorio) se resalta que éste es flexible al convertirse dependiendo de las actividades: de profano a sagrado, de privado a comunitario y viceversa. El acontecimiento privado se vuelve colectivo, por ejemplo, los invitados a una boda no se limitan exclusivamente a los familiares y conocidos, toda la comunidad es partícipe y el patio de la casa se extiende a la calle. De la misma forma esto sucede cuando los encargados de las festividades religiosas en las cosmovisión como parte de una tradición prehispánica y del catolicismo impuesto por los españoles. Al decir de Blanca Cárdenas (2006) la tradición oral, las fiestas religiosas y profanas, atestiguan un arraigo cultural que rompe con la barrera del tiempo y se siguen manifestando como rituales híbridos y reminiscencias de la memoria antigua. Los cultos y creencias de origen mesoamericano se reelaboraron con la implantación del catolicismo, pero en este proceso de imposición de una nueva religión, se mantuvo como parte fundamental el sentido animado $y$ sagrado de la naturaleza (Azevedo, 2018).

Entre los purépechas aquello que se mantiene como parte de la tradición se suele mencionar de manera genérica como "la costumbre". La vida social y comunitaria se sustenta en un sistema de normas que se basan en el principio de la reciprocidad y de vida en comunidad.

Por otro lado, la antropóloga Aída Castilleja (2007) observó tres maneras que el purépecha pauta el tiempo: el más antes, el antes y el ahora. El más antes hace referencia al tiempo previo al contacto con los españoles, el antes se refiere a un pasado difuso cuyos inicios están anclados en el periodo colonial y se extiende al tiempo de los bisabuelos y abuelos y el ahora está

Figuras 14 y 15 - Vida social y comunitaria.

Convivio en una unidad doméstica en Uricho, cuenca lacustre de Pátzcuaro
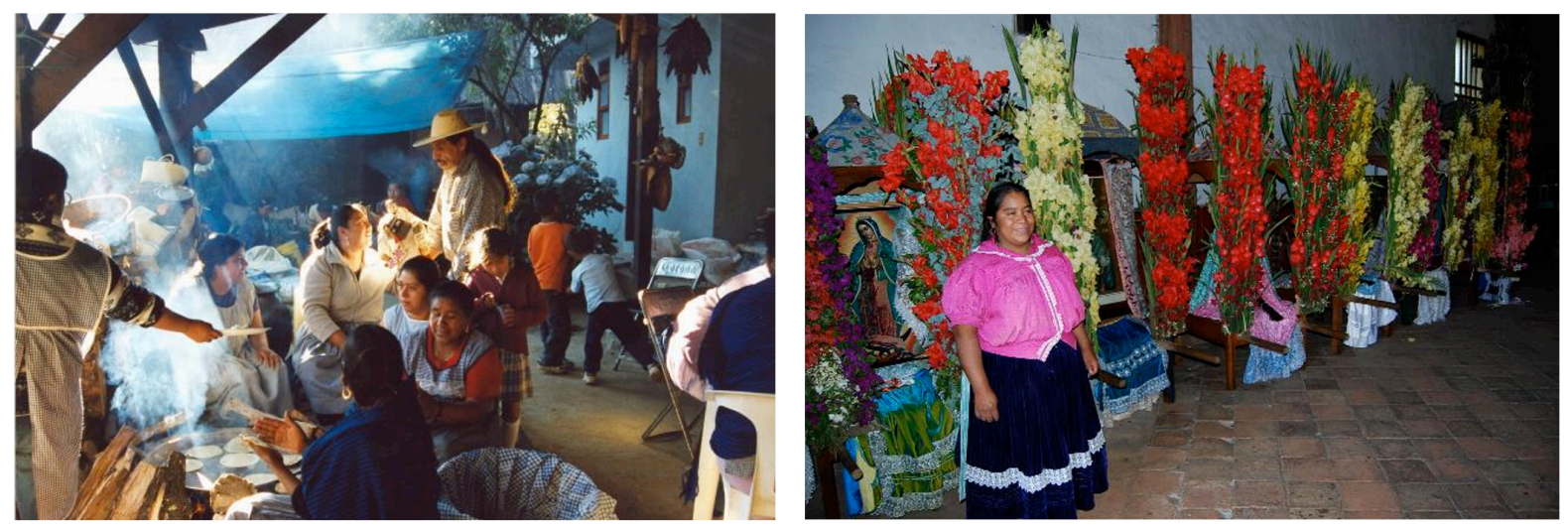

Fuente: Archivo Torres Salomao (2007).

comunidades -los cargueros ${ }^{\text {ii } ~-~ t r a n s f o r m a n ~ l o s ~}$ espacios de sus casas, en espacios comunales. Es así que, el espacio en la cultura purépecha se concibe de forma muy distinta del mundo occidental; se articula alrededor de un tiempo ceremonial y de un espacio comunal (Jacinto, 1988).

Esta forma peculiar de concepción del espacio y del tiempo tiene su antecedente en la referido al presente inmediato. En esta forma de ser del purépecha, el espacio puede ser entendido como un texto de larga duración, como sostén de la memoria, de elementos que permanecen y también como sustrato en el cual se presentan cambios (Figuras 14 y 15). 


\section{Territorio cultural purépecha: patrimonio inmaterial \\ purépecha:
material e}

Después de presentar una semblanza de la cultura purépecha desde distintas aristas, en esta sección se invita a la reflexión sobre los avances en el concepto de patrimonio cultural y cómo direccionar una gestión holística del patrimonio cultural purépecha.

En épocas recientes se ha producido innumerables reflexiones, desde distintas disciplinas, acerca del patrimonio cultural. Esta palabra aparece con tanta frecuencia en el discurso actual que todo cuanto nos rodea, desde lo individual a lo colectivo y de lo concreto a lo inmaterial, puede convertirse de pronto en patrimonio. En las sociedades actuales el fantasma de la ruptura con el pasado ha conducido a buscar en el patrimonio un refugio necesario como consecuencia de los cambios excesivamente rápidos que están sucediendo en nuestro tiempo. En ese sentido han coincidido destacados filósofos, historiadores, sociólogos, antropólogos como Hans-Georg Gadamer, Paul Ricoeur, Pierre Nora, Maurice Halbwachs, Martín Heidegger, Clifford Geertz, Llorenç Prats, entre otros.

Por otro lado, se ha visto una evolución en el concepto de "patrimonio cultural" que se amplía gracias a la contribución de la disciplina antropológica, incorporando los aportes de grupos y segmentos sociales que antes se encontraban al margen de la historia y de la cultura dominante. Así, la noción de cultura supera la visión de un "conjunto de cosas", pasando a valorarse los procesos culturales en los cuales el tema de lo inmaterial cada vez más gana relevancia.

En el caso del patrimonio cultural purépecha como en muchas otras culturas, el propósito de la conservación del patrimonio cultural se ha enfocado en los productos culturales materiales, sobre todo en los bienes muebles e inmuebles que ostentan el sello de tiempos pasados y calidad artística y estética. Con relación a lo inmaterial, este patrimonio ha sido visto de manera aislada. Las políticas conservacionistas -en el caso de estudio- no han superado una visión unilateral.

Se considera, por lo tanto, la necesidad de replantear miradas reduccionistas y el arribo a posturas más recientes sobre el tema de la cultura, patrimonio y territorio cultural. No se puede perder de vista la relación fundamental entre el patrimonio cultural inmaterial con los paisajes naturales y lugares construidos. Es fundamental explicar las circunstancias por las cuales los actores del espacio habitado construyen el paisaje en términos de representaciones mentales, como imágenes de lo que perciben en su entorno; aspectos que tienen que ver con el lenguaje, la territorialidad, habitabilidad e identidad, y en términos de largo plazo, se pueden definir como procesos adaptativos y de transmisión cultural (Fuentes, 2013).

El territorio cultural purépecha no es una configuración vacía o un escenario desierto sino animado, ya que la presencia del humano es clave y, por otro lado, son realidades físicas individualizables, organizaciones dinámicas y de sentidos. Se observa en la mayor parte de la literatura producida sobre la cultura purépecha, estudios que analizan únicamente lo "físico", otros se centran en una filosofía conservacionista de la naturaleza, en otros casos la faceta "artística" es lo destacado o trabajos de carácter historicista que documentan sobre distintas etapas históricas en la conformación de esta cultura. Estos trabajos se traducen habitualmente en una memoria descriptiva de los espacios, pero escasamente se detienen en reflexionar de forma sistémica el territorio en relación a las dinámicas culturales que lo han construido y que lo dotan de significado.

La propuesta que plantea Francisco Fuentes (2013) es coincidente con los argumentos presentes en este trabajo. Con la mirada puesta en las visiones más recientes sobre el tema de la cultura, patrimonio, paisaje cultural, transdisciplina, entre otros, este arquitecto desmenuza la relación fundamental entre el patrimonio cultural inmaterial con los paisajes naturales y lugares construidos en el ejemplo la cultura purépecha. Explica las circunstancias por las cuales los actores del espacio habitado construyen el paisaje en términos de representaciones mentales, como imágenes de lo que perciben en su entorno; aspectos que tienen que ver con el lenguaje, la territorialidad, habitabilidad e identidad, y en términos de largo plazo, se pueden definir como procesos adaptativos y de transmisión cultural. El autor parte de la premisa que el dualismo cartesiano de separar mente y cuerpo, sujeto y objeto, o naturaleza y cultura, ha impedido observar problemas emergentes como la globalización y el multiculturalismo (Fuentes, 2013).

Por lo tanto, en el estudio y gestión del territorio cultural purépecha se debe abordar bajo una mirada holística, con una perspectiva dinámica, con apoyo metodológico del pensamiento complejo y rebasando los modelos y fronteras disciplinares. 


\section{Los retos de la "Patrimonialización" en contextos culturales como el purépecha}

El proceso de "patrimonialización" se constituye como una nueva práctica que consiste en asignar nuevos significados e interpretaciones a un bien considerado por las sociedades como "patrimonio cultural". Este proceso confiere a la interpretación del patrimonio su carácter polisémico e ideológico.

Según Ramos (2017) apoyada en Prats (1998) polisémico porque trabaja mediante el símbolo. El símbolo, de forma abstracta, evoca o representa una identidad o una realidad. Su principal característica radica en que posee la " $[. .$. capacidad para expresar de una forma sintética y emocionalmente afectiva una relación entre ideas y valores [...] el símbolo tiene la capacidad de trasformar las concepciones y creencias en emociones, de encarnarse, y de condensarlas y hacerlas, por lo tanto, mucho más intensas [...]" (Ramos, 2017, p. 2).

Al respecto se menciona que el significado que adquiere un símbolo depende siempre del "contexto y del consenso del que goce y, además, puede adquirir uno o más significados a la vez, de aquí el carácter polisémico del patrimonio cultural" (Ramos, 2007, p. 2). Otro aspecto a considerar está relacionado con la activación del patrimonio "[...] lo que implica que un referente patrimonial es seleccionado del campo imaginario para pasar a formar parte de la realidad de una sociedad como patrimonio cultural" (Ramos 2017, p. 3).

Es importante mencionar que las activaciones patrimoniales en la mayoría de las veces se pueden entender como una "[...] estrategia política y afectan las identidades políticas básicas: locales, regionales y nacionales" (Ramos 2017, p. 3). En el contexto latinoamericano, en la mayoría de los casos, las activaciones están directamente vinculadas al poder político; las activaciones del patrimonio están incentivadas por los gobiernos nacionales, estatales y locales, con la idea de generar recursos vinculados principalmente al tema del turismo cultural.

Al respecto Prats (2005) dice lo siguiente:

[...] la adopción del sistema de representación patrimonial como soporte de identidades e ideologías, tienen una gran importancia para el poder político, tanto a nivel nacional o regional como a nivel local (aunque sea menos aparente). En general (con notorias excepciones), puede decirse que, con el tiempo, se han tornado más complejos, discretos y sofisticados, pero no por ello menos efectivos. En torno a ellos, en torno a las activaciones patrimoniales, se plantea un segundo plano de negociación, mucho más peliagudo que el anterior. Los actores principales son el poder político y la sociedad, uno y otra de por sí suficientemente complejos como para que el proceso (y su análisis) no resulte precisamente simple y fluido, aunque la toma de decisiones precipitadas (que tendrá consecuencias posteriores) haga que, a veces, lo pueda parecer (p. 67).

En el caso de la cultura purépecha se observa que las activaciones patrimoniales han incidido de manera deliberada en el mercado "lúdico- turístico-cultural", aspecto que amerita cuidado y una revisión meticulosa para no permitir la trivialización del patrimonio. Lo anterior ha provocado una progresiva "espectacularización” de muchas activaciones patrimoniales recientes. Como ejemplo está la festividad del Día de Muertos en Michoacán, una de las expresiones de mayor transcendencia para las comunidades indígenas purépechas, ritual de profunda significación que está considerado como "Obra maestra del patrimonio oral e intangible de la humanidad por la UNESCO” (Azevedo, 2018, p. 109).

Para los purépechas esta celebración tiene que ver con su manera especial de concebir la vida en todas sus dimensiones; además del carácter agrícola, la fiesta de ánimas expresa la importancia que para la cultura purépecha tienen los difuntos, quienes, en su calidad de ancestros, están presentes en la vida social. Esta festividad está regulada por normas propias y que son conocidas y transmitidas por "la costumbre"; así, no se puede hablar de principios rígidos y uniformes, hay maneras particulares en la celebración que distingue una comunidad de otra (Castilleja, 2007).

En la ribera del Lago de Pátzcuaro y sus islas esta celebración es muy difundida y muy vistosa, en los panteones las tumbas se adornan con los elementos característicos de la celebración; en otras regiones purépechas como la Sierra, La Cañada y la Ciénega de Zacapu, cada población tiene su manera propia de hacer la fiesta. Hay comunidades en las cuales se celebra con un altar en la casa, en otras el adorno es de grandes dimensiones y reúne la familia extensa, parientes y amigos.

Se observa con preocupación cómo en los últimos años esta celebración ha sido utilizada por empresas particulares de turismo que organizan recorridos a las comunidades purépechas, para que los visitantes vean como los locales velan a sus difuntos en los panteones, a veces sin respeto a las tradiciones culturales y sin mayores beneficios económicos a las comunidades indígenas. Por lo tanto, no se puede soslayar los riesgos de la 
"patrimonialización" cuando se trata de expresiones culturales de larga tradición y de profundo contenido simbólico (Figuras 15 y 16).

Figuras 16 y 17 - Festividad del Día de Muertos. En la primera imagen abajo panteón de Tzintzuntzan en la cuenca lacustre de Pátzcuaro y en la segunda imagen abajo celebración en Aranza, Sierra purépecha
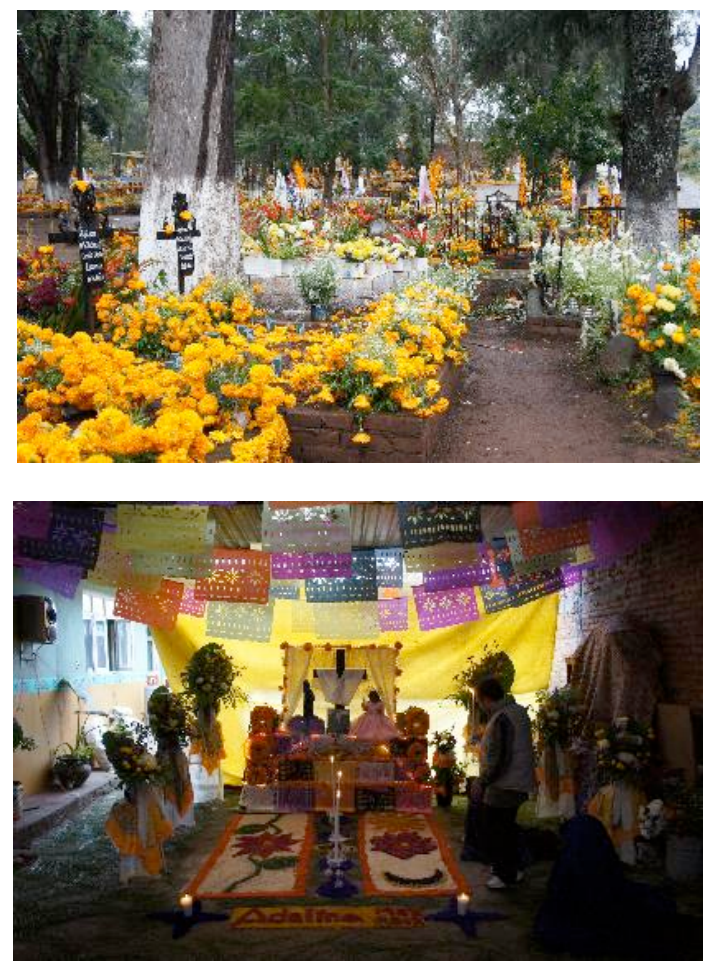

Fuente: Archivo Torres Salomao (2014).

\section{Reflexiones finales: Gestión sostenible del territorio cultural purépecha}

Como se dijo con anterioridad, la sostenibilidad no debe ser vista exclusivamente desde una mirada física de adecuación del espacio habitable al medio natural, es una condición necesaria para el desarrollo del conjunto de las actividades humanas, inclusive el de la cultura, y por lo tanto de la conservación de los bienes culturales que ella genera.

En el caso de la región purépecha, varias han sido las propuestas fallidas de conservación y rehabilitación. Lo anterior en virtud de que la región se ha visto como unidades aisladas y no como un territorio cultural impregnado de muestras de un patrimonio inmaterial y de un paisaje ambiental que requieren ser abordados como un todo y no como unidades fragmentadas, en donde se han revisado nada más los objetos culturales patrimoniales (monumentos). La falta de protección legal aunada a los problemas económicos que promueven la migración de los habitantes y con ello la invasión de modelos culturales distintos a lo local, asimismo la inseguridad, han propiciado en las últimas décadas, la imposición de nuevos paisajes, nuevos hábitos de vida en los cuales cada vez es mayor el alejamiento a la naturaleza. Hace falta una gestión sostenible que adopte una actitud de transversalidad en la lectura de este territorio cultural.

Es importante reafirmar que las formas y modos de vida de las comunidades purépechas siguen ancladas hasta nuestros días a costumbres milenarias y fuertes tradiciones culturales. Como dice Fernández "se trata de postular la preponderancia de un patrimonio ambiental en tanto manifestación de relaciones sociedad / naturaleza en lugar del clásico concepto de patrimonio cultural" (Fernández, 2005, manuscrito s/p). La noción de patrimonio ambiental conlleva a una concepción que extrapola la visión coleccionista y de excepcionalidad de los objetos culturales. Este argumento ambiental opuesto al naturalismo ecologista, es una propuesta sumamente interesante que lleva a evaluar la significación del sitio como "pre-determinación del gesto objetual social" (Fernández, 2005, manuscrito $\mathrm{s} / \mathrm{p})$.

Esta nueva perspectiva plantea que el espacio es la materia prima sobre el cual los humanos manifiestan sus prácticas (Bello, 2006), por lo que se puede decir que se construye socialmente, que es un producto social (Lefebvre, 1974), el cual se transforma y se reinterpreta cotidianamente por las poblaciones que lo viven en función de su desarrollo tecnológico, de sus necesidades, de sus instituciones, de su estructura social, económica y política, es decir de su cultura. También se plantea que el espacio produce a la sociedad con particularidades resultantes de sus ineludibles formas materiales, que muchas veces vienen del pasado, y representan restos de otros tiempos históricos pero que siguen presentes $y$ frente a los cuales las sociedades recrean nuevos usos, funciones y sentidos, o más bien se ven necesitadas de hacerlo (Lindón, Herniaux y Aguilar, 2006). Esta postura tiene una aplicación clara en la protección, conservación y políticas de desarrollo sostenible de la región purépecha.

Aspecto fundamental en el tema del patrimonio cultural material e inmaterial se refiere a la fragilidad que presentan y el hecho de que existe una limitación clara del potencial del recurso a explotar. Todo recurso natural y cultural es escaso; es decir, tiene un límite, son bienes no renovables. Ningún bien patrimonial es intercambiable con otros de características similares; al contrario, cada 
objeto cultural es único. Por otro lado, no todos los bienes que integran un territorio cultural ofrecen las mismas posibilidades, tienen el mismo valor científico o educativo, son estimables en la misma medida, están por igual a nuestro alcance, ni están del mismo modo amenazados (Ballart y Tresserras, 2001).

En vista de lo expuesto en las líneas anteriores, se resalta la importancia de reflexionar sobre los vínculos solidarios de significación y protección entre el paisaje, los modos de producción y el patrimonio cultural, adoptando una actitud de transversalidad en la lectura del territorio, en donde los aspectos naturales y culturales se entrelazan, propiciando abordajes para identificación de valores y comprensión del patrimonio más complejos y múltiples. Para el caso del territorio cultural purépecha es fundamental la construcción de políticas públicas que consideren la diversidad de manifestaciones culturales y su patrimonio, que propicien el desarrollo de una sociedad que se pretenda sostenible.

La búsqueda del equilibrio entre los intereses económicos y la preservación del patrimonio cultural es posible en la medida en que los valores solidarios y simbólicos permanezcan a través de prácticas participativas, que visualicen mayor respeto y equidad en los procesos de reconocimiento, valoración y protección del patrimonio cultural y natural. Por lo tanto, la teoría de los sistemas complejos y la transdisciplina se sugiere como el andamiaje teórico para arribar a la sostenibilidad de este territorio cultural.

\section{Referencias bibliográficas}

Azevedo, E. (2008). La vivienda purépecha. Habitabilidad y forma de vida. En E. Azevedo Salomao (Coordinación), La vivienda purépecha. Historia, habitabilidad, tecnología y confort de la vivienda purépecha. Morelia, México: Universidad Michoacana de San Nicolás de Hidalgo, Consejo Estatal de Ciencia y Tecnología.

Azevedo, E. (2018). Religiosidad y espacio habitable en la cultura indígena purépecha, México. Los riesgos de la "patrimonialización”. Revista Relicário, volumen, 5 (10), 95-115. Recuperado de: https:// revistarelicario.museudeartesacraube rlandia.com.br/index.php/relicario/article/v iew $/ 33$

Azevedo, E. y Fuentes, F. (2017). Paisaje cultural y conservación del patrimonio: Reflexiones en torno a ejemplos mexicanos. Revista Relicário, volumen, 4 (7), 43-67. Recuperado de: https://revistarelicario.museudeartesacraube rlandia.com.br/index.php/relicario/article/v iew $/ 50$

Azevedo, E. y Vale, M. (2018). Patrimonio Cultural, habitabilidad y sostenibilidad. Miradas al pensamiento complejo. Revista Húmus, volumen, 7 (23), 67-86. Recuperado de: http://www.periodicoseletronicos.ufma.br/i ndex.php/revistahumus/article/view/9040

Ballart, J y Tresserras, J. (2001). Gestión del patrimonio cultural. Barcelona, España: Editorial Ariel.

Bello, A. (2006). Espacios construidos, territorios resignificados; etnicidad y lucha por la tierra entre los purépechas de Nurio, Michoacán (Tesis de doctorado en antropología social). Universidad Nacional Autónoma de México, México.

Cárdenas, B. (2006). Tipología. Cultura y relatos p’urbépecha. Morelia, México: Universidad Michoacana de San Nicolás de Hidalgo, Universidad Paul Valéry Montpellier III.

Castilleja, A. (2007). Construcción social y cultural de categorias referidas al espacio. Un estudio de pueblos purépecha (Tesis de doctorado en antropología). Escuela Nacional de Antropología e Historia (ENAH), México.

Fernández, R. (2005). Gestión integral del patrimonio. San Luis Potosí, México: Facultad del Habitat, UASLP. Manuscrito inédito.

Fernández-Villanueva, E. y Cárdenas E. (1999). Arqueología de la cuenca de Pátzcuaro. Un estudio de las relaciones de poder y su manifestación en el espacio y en la arquitectura. Pátzcuaro, México: texto preparado para la reunión del grupo K'uaniskuiarani, de estudiosos del pueblo purépecha. Manuscrito inédito.

Fuentes, F. (2013). Aspectos intangibles del P'urbé echerio. Hacia un estudio integral de los paisajes de la cuenca lacustre de Pátzcuaro. Morelia, México: Universidad Michoacna de San Nicolás de Hidalgo.

García, E. y Vaca, A. (2018). De cultura, modernidad y sostenibilidad. En E. García y A. Vaca (Coordinadores), Sostenibilidad: ¿un extraño a la modernidad? (pp.5-19). Guadalajara, México: Universidad de Guadalajara.

Guzmán, J. C. (editor) (2007). Guía de arquitectura y paisaje Michoacán. Morelia-Sevilla: Junta de Andalucía, Ministerio de Cultura, España, Gobierno del Estado de Michoacán.

Jacinto, A. (1988). Mitología y Modernización. Zamora, México: El Colegio de Michoacán, Gobierno del Estado de Michoacán.

Lefebvre, H. (1974). La producción del espacio. Paris, Francia: Anthropos. 
López R., Platas, F., Romero G. y Salceda, J. (2014). La complejidad y la participación en la producción de arquitectura y ciudad. México: Universidad Autónoma de México.

Lindón, A., Herniaux, D. y Aguilar, M. (2006). De la espacialidad, el lugar y los imaginarios urbanos: a modo de introducción. En A. Lindón, D. Herniaux y M. Aguilar (Coords), Lugares e imaginarios en la metrópolis. México: Anthropos, Universidad Autónoma Metropolitana- Iztapalapa.

Morin, E. (2007). Introducción al pensamiento complejo. Barcelona, España: Editorial Gedisa.

Paredes, C. (2017). Al tañer de las campanas. Los pueblos indigenas del antiguo Michoacán en la época colonial. México: Centro de Investigación y Estudios Superiores en Antropología Social, Comisión de Desarrollo de los Pueblos Indígenas.

Paredes, C. (2008). La vivienda purépecha. Notas en torno a su historia y la habitabilidad en la época colonial. En E. Azevedo Salomao (Coordinación), La vivienda purépecha. Historia, habitabilidad, tecnología y confort de la vivienda purépecha. Morelia, México: Universidad Michoacana de San Nicolás de Hidalgo, Consejo Estatal de Ciencia y Tecnología.

Prats, L. (2005). Concepto y gestión del patrimonio local. Cuadernos de antropología social, (21). Recuperado de http://www.scielo.org.a r/scielo.php? script $=$ sci_arttext\&pid $=S 1850$ 275X2005000100002

Prats, L. (1998). El concepto de patrimonio cultural. Política y Sociedad, (27), 63-76.

Ramos, D. (2017). Sobre la construcción del patrimonio cultural y el proceso de patrimonialización. Revista cultural (14). Recuperado de http://revistamito.com/laconstruccion-del-patrimonio-culturalproceso-patrimonializacion/

Ribeiro da Costa, F. (2014). Comprender la complejidad del patrimonio cultural. En B. Núñez y A. Peregrina (Coordinadoras), Patrimonio y modos de vida. Zapopan, México: El Colegio de Jalisco.

\footnotetext{
Notas

${ }^{\mathrm{i}}$ Con relación a los términos para designar la cultura estudiada, es importante comentar que el término tarasco desde el punto de vista histórico es el etnónimo más utilizado. El término purépecha ha cobrado mayor fuerza hasta entrado el siglo XX, estando acompañado de los movimientos de reivindicación étnica del grupo,
}

tanto en los medios académicos como entre los propios hablantes del idioma (Paredes, 2017).

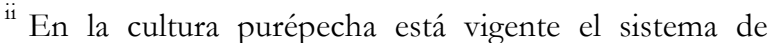
cargos tradicionales, reminiscencia de la organización social de la etapa prehispánica fusionado con las normatividades emanadas del proceso de conquista espiritual y administrativa ocurrida en el siglo XVI. El cargo es una encomienda, es una investidura, un mayorazgo y entre los miembros de las comunidades purépechas es considerado como sagrado, se asume la responsabilidad de ser un custodio de una tradición cultural que se mantiene y se transmite a nuevas generaciones. 